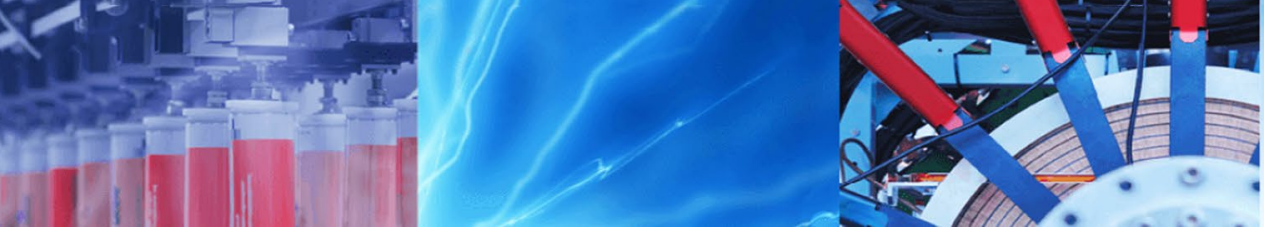

Research Article

\title{
Corrosion inhibition of 316L-type stainless steel under marine environments using epoxy/waste plastic soot coatings
}

\author{
Jay M. Korde ${ }^{1} \cdot$ Akhil V. Sreekumar $^{2} \cdot$ Balasubramanian Kandasubramanian $^{1}$ (i)
}

Received: 10 December 2019 / Accepted: 16 June 2020 / Published online: 23 June 2020

(c) Springer Nature Switzerland AG 2020

\begin{abstract}
$316 \mathrm{~L}$ grade stainless steel is widely utilized in industrial applications owing to its exceptional corrosion resistance. However, it is less resistant to aggressive marine environments that contain salt-based seawater. In the present study, we report effective anti-corrosive epoxy polymer coating engineered with carbon soot nanoparticles (derived from waste polyolefin plastics) and coated on a $316 \mathrm{~L}$ steel substrate via controlled pneumatic fluid atomization technique. Morphological analysis of derived carbon soot nanoparticles revealed an average diameter to be in the range of 41-62 $\mathrm{nm}$. Corrosion inhibition performance of the coatings was studied under aggressive chlorine-based environments via polarization plots, i.e., Tafel plots, and by natural salt spray test for the total duration of 20 days. The scratch test and the solvent resistance rub test revealed adherence to the developed coatings with a $316 \mathrm{~L}$ steel surface. The developed coatings were found to be uniform, crack-free, and well bonded with the surface of steel substrates. Successive experimental results of the developed coatings indicated enhanced corrosion inhibition properties, which imply its practical applicability for under-water marine applications.
\end{abstract}

Keywords $316 \mathrm{~L}$ stainless steel · Epoxy · Anti-corrosive coating · Corrosion inhibitor · Carbon soot

\section{Introduction}

Corrosion is one of the crucial issues faced by metals and their alloys, which are vital in an extensive array of industrial functions, by resulting in decay and loss of material because of a chemical attack, thereby affecting the structural integrity, durability, and reliability of the metals [1-3]. Corrosion is an assorted reaction procedure that occurs on the metallic/alloys substrates at the microscopic level. At the same time, its manifestation is visible at the macroscopic scale, which results in premature failure of metallic parts, thus causing financial losses, environmental contamination, and/or injury/death [4-6]. Surveys have validated that every year an average of $4.2 \%$ of the total gross domestic product (GDP) of the industrialized country is lost owing to corrosion-related problems [7]. The USA annually spends nearly US $\$ 437$ billion on rusting-associated snags, wherein a maximum of this budget is apportioned to an inspection of corroded fragments of edifices, refurbishing of structures via copious approaches comprising protective coatings (polymeric, paints, surface treatments, etc.), and discarding the hazardous waste materials $[8,9]$. For achieving multifarious goal of decreasing financial costs, improving corrosion resistance and augmenting safety at work, extension of service life of existent structures should be improved [10, 11].

\section{Electronic supplementary material The online version of this article (https://doi.org/10.1007/s42452-020-3096-2) contains} supplementary material, which is available to authorized users.

Balasubramanian Kandasubramanian, meetkbs@gmail.com | ${ }^{1}$ Nano Surface Texturing Laboratory, Department of Metallurgical and Materials Engineering, Defence Institute of Advanced Technology (Deemed University), Ministry of Defence, Girinagar, Pune 411025, India. ${ }^{2}$ Department of Ship Technology, Cochin University of Science and Technology, South Kalamassery, Cochin, Kerala 682022, India. 
Protective polymeric coatings have been explored for the protection of metal products against corrosion, as polymeric coatings play a physical barrier between metallic substrate and corrosive environment, which disrupts the flow of electrons from anode to cathode and/or thereby adsorbing reaction products produced at cathode sites $[3,12-14]$. Epoxy resins are extensively adapted commercially for such coatings in aggressively corrosive environments owing to their exceptional characteristics chemical resistance, adherence toward metallic substrates, excellent processability, ability to incorporate nanomaterials, high dielectric strength, insulating nature, and low cost [15-18]. Epoxy coatings comprise hydrophilic hydroxylbased moieties within their cured network, which leads to hydrolytic degradation due to weak resistance to humidity $[19,20]$. Upon exposure of corrosive electrolyte, initiation and propagation of cracks occur within epoxy coatings. Thus, it facilitates the transfer of corroding agents like oxygen, water, and reactive ions like $\mathrm{Cl}^{-}$and $\mathrm{H}^{+}$via defects inside coating, thereby resulting in the decreased coating adherence and ultimately causing the corrosion of metal specimens below the applied coating [21,22]. Thus, it motivated the researchers to improve the barrier property and corrosion protection efficacy of epoxy-based coatings $[23,24]$.

Recent scientific investigators have demonstrated that the barrier and corrosion protection characteristics of the epoxy polymer can improve upon the introduction of a second phase, which is miscible with the epoxy polymer $[25,26]$. In recent periods, due to lower pricing and mass production, the majority of the polymers are discarded readily after their utilization, which results in a steep rise of plastic waste [27-29]. Most of the generated plastic waste belongs to a class of polymers are based on polyolefins $\left[\left(\mathrm{C}_{n} \mathrm{H}_{2 n}\right)_{n}\right]$, which exhibit carbon content of $\sim 85.7 \mathrm{wt} \%$, and is found to be a useful source for the production of nano-sized carbon materials [30-32]. Nanosized carbon soot particles are found to possess exceptional characteristics like barrier resistance, large surface area ratio, and elastic stiffness. Thus, these nano-carbon soot particles have been utilized as an additive, i.e., second phase materials, in the epoxide coatings for the reduction of micropores and for restraining the diffusion path of highly reactive and corrosive species [22, 33, 34].

Environmentally benign, durable, and protective epoxy coatings could be developed by the incorporation of nanoparticles due to their easy dispersion and ability to fill the micropore cavities, which results in low crack deflection, crack bowing and crack bridging [35-37]. Literature reports that the incorporation of nanoparticles like halloysite, nano-clay, and carbon particles in epoxy coatings shows improvement of the fracture toughness [38]. The researchers have reported unique methodologies for achieving the homogenous particle distribution via chemical methods like sol-gel technique, mechanical mixing via high shear forces, and ultrasonication [38]. Chen et al. [39] reported the effect of well-dispersed carbon particle-based epoxy coatings on the friction and the corrosion resistance of the materials. Gu et al. [40] demonstrated that a significant increase in anticorrosion characteristics of the materials could be achieved via effective dispersion of graphene in waterborne epoxy resins using non-covalent functionalization.

Considering the importance of smart protective coatings, the Indian Ministry of Defence has been funding comprehensively for the development of smart protective coatings [1, 41-52]. One of the most promising methodologies for developing the anti-corrosive protective coatings is the fluid atomized spray coating process since it is cost-effective, scalable, and facilitates easy handling. Fluid atomized spray coating process provides adequate inertia to the liquid drops such that the disc-shaped spreading droplets resulting in a thin film coating [53]. Variation in sizes of the liquid droplets of spray-coated films can be achieved by a higher flowrate using the high-pressure spray gun, which forms rough surface architecture on the substrate [54]. The researchers have reported versatile methodologies [1,55-57] for the development of steady, anti-corrosive protective polymeric coatings on various metallic substrates.

The present study reports controlled pneumatic fluid atomization technology for the development of anticorrosive epoxy/carbon soot coatings for the protection of $316 \mathrm{~L}$ stainless steel substrates for marine engineering applications [1]. In this sense, the present study reports development of carbon soot functionalized epoxy-based anti-corrosive coatings for protection of on the surface engineered $316 \mathrm{~L}$ steel substrates. The anti-corrosion performance of the epoxy/carbon soot coatings via polarization plots, i.e., Tafel plots, salt spray test, solvent rub test, and $\mathrm{NaCl}$ exposure test. The scratch test and solvent rub test revealed the adherence and the solvent resistance of the developed coatings. Polarization curves, i.e., Tafel plots, of epoxy/carbon soot coated $316 \mathrm{~L}$ substrates, revealed a decreasing trend for corrosion current density $\left(I_{\text {corr }}\right)$, corrosion rate $(\mathrm{gm} / \mathrm{h})$, and the simultaneous increase in corrosion potential $\left(E_{\text {corr }}\right)$ against corrosive atmospheres (3.5 $w t \% \mathrm{NaCl}$ solution), thus confirming the anti-corrosion efficiency of the developed epoxy/carbon soot coatings.

\section{Experimental work}

\subsection{Materials}

Stainless steel $316 \mathrm{~L}$, used in the present study, was supplied by the Naval Materials Research Laboratory 
(NMRL—DRDO), Ministry of Defence, India, having a compositional array as specified in Table 1. Araldite LY 1564 (epoxy resin) and Aradur 3486 (hardener) were procured from Huntsman Corporation, India. Polyolefin extruded plastic waste generated on twin-screw extruder (Lab-tech Engineering Company, Thailand) was utilized as a source of carbon soot nanoparticles. Glass substrates, having dimensions of $75 \times 25 \times 3 \mathrm{~mm}$, were purchased from Fisher Scientific, India. Methanol purchased from Vetec ${ }^{\mathrm{TM}}$ having a purity of $99 \%$ with a boiling point of $64.7{ }^{\circ} \mathrm{C}$, acetone procured from Sigma-Aldrich Corp., India, boasting purity of $99.8 \%$ with a boiling point of $56^{\circ} \mathrm{C}$, and ethanol bought from Sigma-Aldrich Corporation, India, enclosing purity of $99.7 \%$ with a boiling point of $78.37^{\circ} \mathrm{C}$, were used as cleansing agents. De-ionized water, having a purity of 18.3 $\mathrm{M} \Omega . \mathrm{cm}$, was acquired from the water purification system (Model: Nanopure Barnstead, Make: Cole-Parmer, India) installed in the department of chemistry. All chemical dispersions and solvents were used as received without any purification treatments.

\subsection{Generation of carbon soot particles}

Carbon soot nanoparticles were captured on a glass substrate via controlled combustion of polyolefin-based plastic waste, as illustrated pictorially in Fig. 1. Before their utilization, glass substrates were subjected to ultrasonication in ethanol solvent using bath sonicator (Model: El-6LH-SP, Make: Electrosonic Industries, India), at a frequency of 20 $\mathrm{kHz}$, power of $20 \mathrm{~W}$, for $20 \mathrm{~min}$, with an interval time of $05 \mathrm{~s}$. Further, glass substrates were ultrasonicated in de-ionized water for thorough cleansing for removing any trace of impurities. Primarily, polyolefin plastic waste samples were cut in small pieces (dimension $\sim 10 \times 10 \mathrm{~mm}$ ) and placed in a silica crucible, under an enclosed perforated chamber, with holes of $5 \mathrm{~mm}$ diameter. Carbon soot nanoparticles emitted on the combustion of plastic waste were collected on glass substrates positioned at $50 \mathrm{~mm}$ above the flame. During the carbon soot accumulation, the setup was maintained to possess Haier laminar flow, wherein a uniform downflow velocity of $0.30 \mathrm{~m} / \mathrm{s}$ was observed for flames [58]. Additionally, a higher rate of accumulation of carbon soot nanoparticles is attributed to the lean combustion of plastic waste, and since complete carbon accumulation procedure was conducted in the designed chamber and within a controlled combustion atmosphere (laminar), it makes sampling procedure extremely reproducible [59,

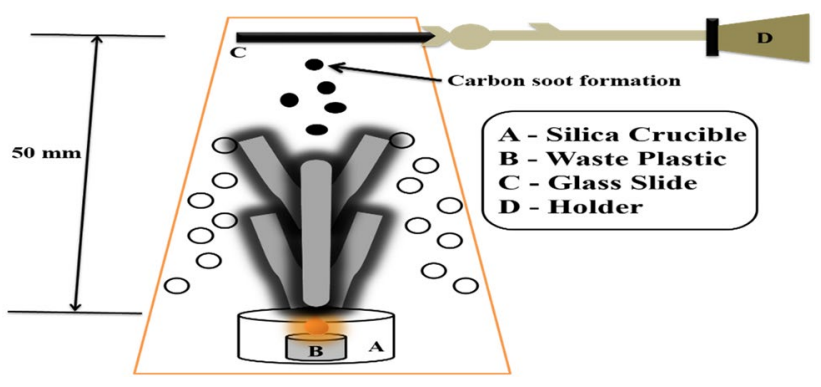

Fig. 1 Setup for deriving carbon soot particles

60]. The glass substrates accumulated with carbon soot nanoparticles were then subjected to ultrasonication in methanol for cleansing, followed by air drying.

\subsection{Surface treatment and coating of $316 \mathrm{~L}$ stainless steel substrates}

Before the coating of epoxy/carbon soot, $316 \mathrm{~L}$ stainless steel substrates were preconditioned on the surface via grinding using commercial silicon-carbide-based emery paper for obtaining uniform coating. Conditioned $316 \mathrm{~L}$ substrates were then subjected to ultrasonication in ethanol solvent using bath sonicator (Model: EI-6LH-SP, Make: Electrosonic Industries, India), at a frequency of $20 \mathrm{kHz}$, power of $20 \mathrm{~W}$, for $20 \mathrm{~min}$. Ethanol solvent-based sonication was performed for removing any strains of grease and/or oil existing on steel specimens. Further, $316 \mathrm{~L}$ specimens were ultrasonicated in polar acetone solvent for dissolving any existing organic and/or inorganic salts, followed by air-drying. These pre-cleaned $316 \mathrm{~L}$ steel substrates were then utilized for direct coating. All precleaned and conditioned specimens were handled using a tweezer for further studies to avoid the contamination of $316 \mathrm{~L}$ substrate from any impurity.

Viscous epoxide resin was thoroughly blended with carbon soot nanoparticles under constant magnetic stirring (speed $\sim 200 \mathrm{rpm}$ ) for $10 \mathrm{~min}$ for proper mixing in various weight percent loadings, i.e., from 1 to $5 \mathrm{wt} \%$. Then the epoxy/carbon soot mixture was cured with a hardener (Aradur 3486, Make: Huntsman India Pvt. Ltd.) under constant magnetic stirring (speed $\sim 100 \mathrm{rpm}$ ) for $10 \mathrm{~min}$. The epoxy/hardener/carbon soot mixture was subjected to ultrasonication at $20 \mathrm{kHz}$ frequency and a power of $40 \%$ via the aid of high-intensity probe sonicator (Mode: PKS-750F, Make: Sonics \& Materials Inc., USA)

Table 1 Composition of 316L stainless steel substrates provided by the NMRL, Ministry of Defence, India

\begin{tabular}{llllllllll}
\hline $316 \mathrm{~L}$ & $\mathrm{C}$ & $\mathrm{Mn}$ & $\mathrm{Si}$ & $\mathrm{P}$ & $\mathrm{S}$ & $\mathrm{Cr}$ & $\mathrm{Mo}$ & $\mathrm{Ni}$ & $\mathrm{Fe}$ \\
\hline Composition (\%) & $<0.03$ & $0-2.0$ & $0-1.0$ & $0-0.5$ & $0-0.02$ & $16.5-18.5$ & $2.0-2.5$ & $10.0-13.0$ & $>62$ \\
\hline
\end{tabular}


for 10 min (sonication time $\sim 05 \mathrm{~s}, \&$ interval time $\sim 05$ s) for ensuring the uniform dispersion of carbon soot nanoparticles. Then the compounded epoxy/hardener/ carbon soot mixture was utilized for coating onto the $316 \mathrm{~L}$ substrates under controlled pneumatic fluid spray atomization process. Figure 2 depicts the schematic illustration of the fabrication of epoxy/carbon soot nanoparticle coating on $316 \mathrm{~L}$ steel substrates.

During fluid spray atomization process, homogeneously dispersed solutions of epoxy/carbon soot (with various loadings) were coated steel substrates via hand spray gun connected to a compressor, which produced a constant air pressure of 3 bar for the controlled generation of the spherical-shaped liquid droplets (spraying distance $\sim 22 \mathrm{~cm}$, tolerance $\sim 1 \mathrm{~cm})[57,61-63]$. Spraying of epoxy/carbon soot dispersion was conducted for a duration of $30 \mathrm{~s}$, which was repeated three times on individual $316 \mathrm{~L}$ specimens for achieving a thin uniform coat of $25 \mu \mathrm{m} \pm 1 \mu \mathrm{m}$. Strong adhesion of the epoxy/ hardener/carbon soot coating with $316 \mathrm{~L}$ substrate was maintained by curing it at a constant temperature of $150{ }^{\circ} \mathrm{C}$ for $2 \mathrm{~h}$ in a hot-oven under normal atmospheric pressure. The thickness of the cured epoxy/carbon soot coating onto the $316 \mathrm{~L}$ substrate was quantified using a calibrated digital gauge meter, which was found to be $25 \mu \mathrm{m} \pm 1 \mu \mathrm{m}$. The volume flux rate of the spray gun was maintained at $0.2 \mathrm{ml} / \mathrm{sec}$ for an applied pressure of 3 bar, which helped in maintaining the uniform and highdeposition rate on a steel substrate. Finally, the coated
$316 \mathrm{~L}$ specimens were then characterized for its adherence and anti-corrosion performance.

\subsection{Characterization}

The combusted carbon soot nanoparticles derived from waste polyolefin plastic were characterized using Field Emission Scanning Electron Microscope (FE-SEM) (Model: JSM-6700F, Make: CarlZeiss AG, Germany) for analyzing the surface morphology of the carbon soot nanoparticles. Coated samples were sputtered via a layer of gold particles for improving the conductivity of specimens for FE-SEM imaging. Raman spectra of carbon soot nanoparticles were measured micro-Raman spectrometer (Model: 6150, Make: Renishaw UK) via argon laser excitation wavelength of $514 \mathrm{~nm}$ at $20 \mathrm{~mW}$ power with illumination spot of size $1 \mathrm{~mm}$ and acquisition time $90 \mathrm{~s}$. The sample for Raman spectroscopy was prepared via a solution drop-casting method. The epoxy/carbon soot nanoparticle-coated $316 \mathrm{~L}$ steel substrates were subjected to scratch test via a Universal Micro-Tribometer (UMT), which exhibited a mechanical testing probe made of tungsten carbide, for analyzing the resistance of coating toward scratching. Similarly, the solvent resistance of the developed coatings was analyzed via the solvent rub test as per the ASTM D5402-93. Cotton cloth was immersed in methyl ethyl ketone solvent and was measured for a maximum number of double rubs across the surface of the coated substrates. The coated substrates were also analyzed via

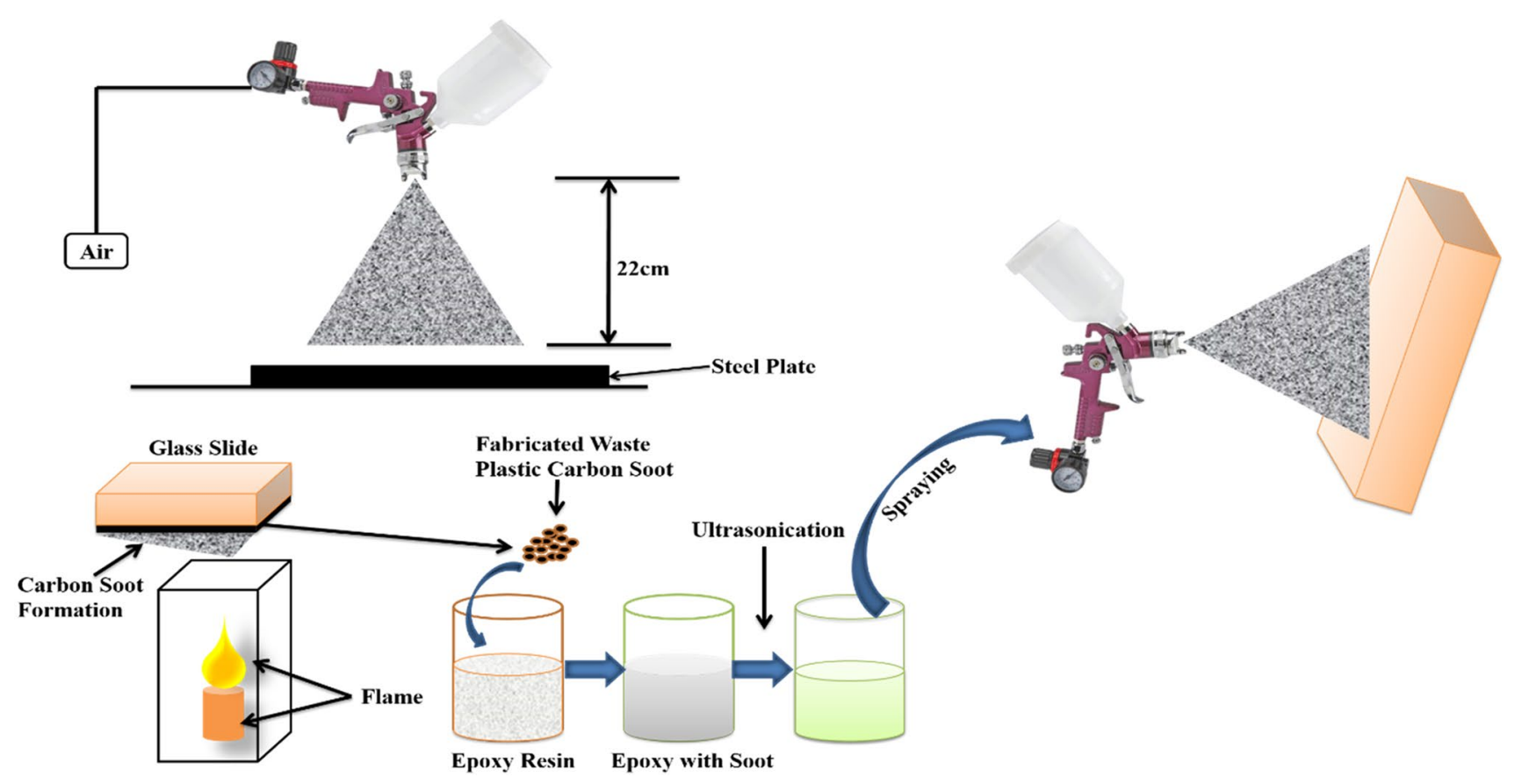

Fig. 2 Schematic of the fabrication process of epoxy/carbon soot nanoparticle coating on 316L steel substrates 
immersion in normal water $(\mathrm{pH} 7)$, saltwater $(\mathrm{pH} \sim 8)$, and $0.1 \mathrm{M} \mathrm{HCl}+3.55 \% \mathrm{NaCl}(\mathrm{pH} \sim 1)$ for simulating and analyzing the real-time effects of corrosive environments on the developed coated substrates. The corrosion resistance of the coated samples was evaluated salt spray test in a salt spray chamber (Make: SUGA CYP-90, Japan) as per the ASTM B-117 standard, where the edge and back areas of the specimens were sealed via transparent tape. The test was conducted at $35 \pm 2{ }^{\circ} \mathrm{C}$ for 20 days, where $5 \mathrm{wt} \% \mathrm{NaCl}$ solution was utilized as the media having a $\mathrm{pH}$ of 6.5-7.2, and the morphology of the substrates was recorded via optical microscopy prior and after the test. Cell coupled with Potentiostat (Model: Gamry Reference system 600, Make: Wilmington, USA) was utilized for studying the anticorrosive behavior of the coated specimens. Three electrodes (placed at $120^{\circ}$ apart) were utilized in a corrosion working cell for performing the polarization experiments, where a saturated calomel electrode acted as a reference electrode, and the coated sample acted as working-electrode. Graphite electrode acted as counter-electrode, and the test was carried across a frequency array of 100-0.01 $\mathrm{Hz}$ with a primary delay of the $50 \mathrm{~s}$ via utilization of simulated seawater ( $3.5 \mathrm{wt} \% \mathrm{NaCl})$ as a corroding atmosphere.

\section{Results and discussion}

\subsection{Microstructure and Raman analysis of carbon soot particles}

FE-SEM analysis revealed the morphology of the generated carbon soot particles, as depicted in Fig. 3. FE-SEM analysis revealed a cluster-type 3D interconnected pattern of carbon soot particles, which are attached as a result of weak van der Wall's forces, and electrostatic charges of attraction $[58,64]$. The average size of the soot nanoparticles was found to be around 41-62 nm, which implies agglomerated morphology depicting chains of carbon nano-sphere type shapes.

Raman analysis revealed the presence of two distinct bands at $1332 \mathrm{~cm}^{-1}$ (D band) and $1590 \mathrm{~cm}^{-1}$ (G band) for carbon soot nanoparticles, which indicate the first-order Raman spectrum, as depicted in Fig. 4. G band represents the characteristic crystalline graphite phase, with a higher-intensity of $\mathrm{G}$ band corresponding to the highly graphitized structure [64]. Highly oriented pyrolytic carbon is indicated by the $\mathrm{G}$ bands observed at $1590 \mathrm{~cm}^{-1}$ for carbon soot nanoparticles. The existence of surface defects of CNTs and amorphous carbon is indicated from $D$ band, which is detected merely for disordered graphite, and a peak at $1332 \mathrm{~cm}^{-1}$ for carbon soot nanoparticles indicates disorder within graphite sheets $[65,66]$.

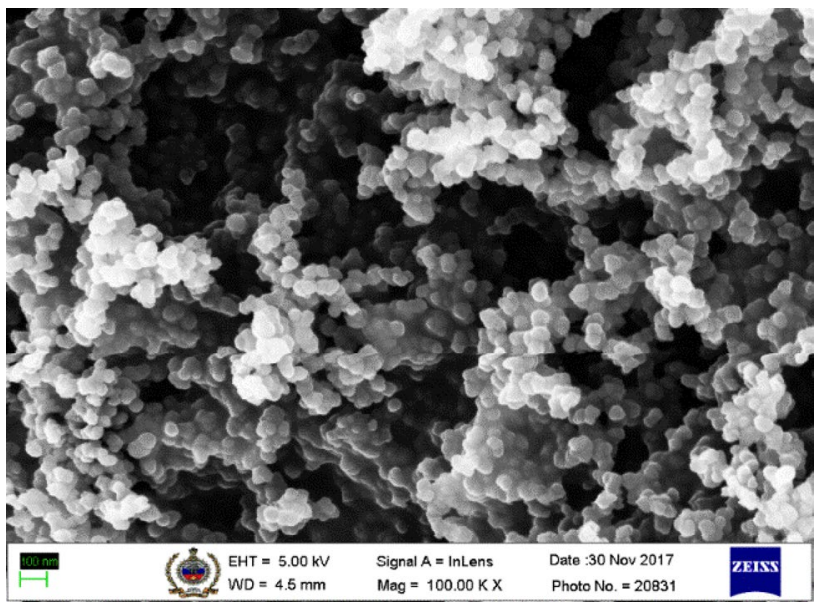

Fig. 3 FE-SEM image of carbon soot particles generated from waste plastic

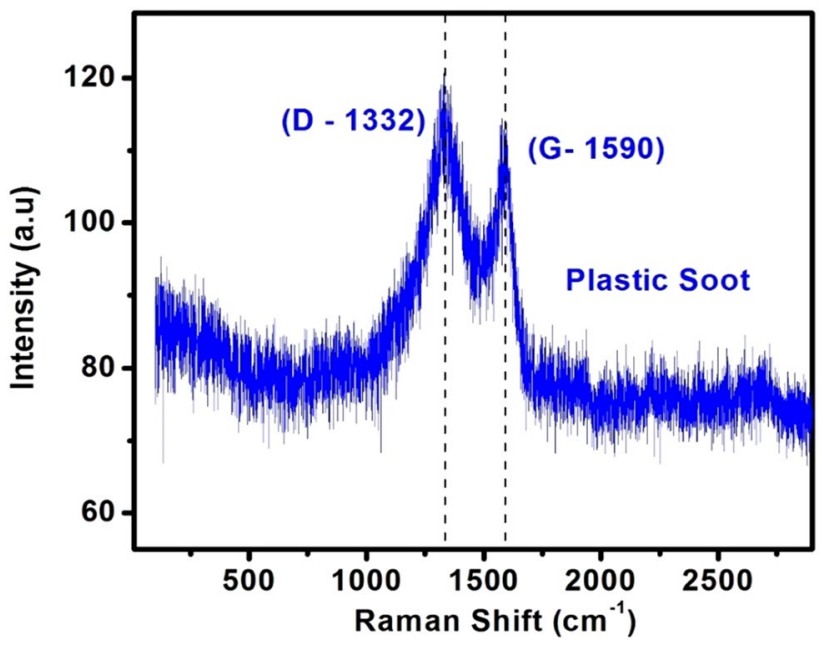

Fig. 4 Raman spectra of carbon soot nanoparticles derived from waste plastic

\subsection{Physio-mechanical and physio-chemical performance of epoxy/carbon soot coating}

Physical characterization of the epoxy/carbon soot coatings was performed using the scratch test, whose performance is influenced by factors like contact geometry, applied load, penetration depth in proportion to layer thickness, the lateral sliding velocity of contact, and the rate of deformation to collectively determine the response of a viscoelastic solid when subjected to scratch test [67, 68]. These parameters govern contact strain, the effective rate of strain, stress-state and magnitudes, and distribution of stresses. The observed values for the scratch test of the devised epoxy/carbon soot nanoparticle coating have been tabulated in Table 2, whereas Fig. 5 depicts the scratch resistance of the developed coatings. The scratch 
test results indicate that the incorporation of carbon soot particles in the coating helps in augmenting the scratch resistance. Beyond 3 wt\% concentration of carbon soot particles, the values of the specimens tend to decrease is attributed to saturation of soot nanoparticles, which leads to the formation of the agglomerates and non-uniform distribution in the coatings. The overall analysis of the scratch test indicates that the $3 \mathrm{wt} \%$ loading of carbon soot particles exhibits optimum performance for the epoxy/carbon soot coatings.

Furthermore, a solvent rub test based on ASTM D540293 standard revealed the chemical resistance performance of the developed epoxy/carbon soot coatings. The epoxy/ carbon soot coated $3016 \mathrm{~L}$ substrates were exposed to twosolvent rub test using a cotton cloth that was immersed in methyl ethyl ketone solvent [69]. Results of the solvent rub tests for epoxy/carbon soot nanoparticle-coated $316 \mathrm{~L}$ substrates are shown in Table 2 . The solvent rub test of a pure epoxy coating ( $0 \mathrm{wt} \%$ carbon soot) shows moderate removal of the coating. The incorporation of carbon soot nanoparticles in the epoxy coating dramatically improved the solvent resistance toward the methyl ethyl ketone, which is evident from the results of the 100 solvent rub test cycles. The coated $316 \mathrm{~L}$ substrates with a higher concentration of carbon soot nanoparticles passed the solvent rub tests with better results. The improved performance of the epoxy/carbon soot coatings is probably due to the uniform distribution of the carbon soot particles in the epoxy matrix which leads to high packing density, grown harder segments, the intact adherence between carbon soot and epoxy, which ultimately results in resisting the penetration of the solvent into the epoxy matrix [68].

The alkali solution resistance of the fabricated compositions of epoxy/carbon soot nanoparticle coating was observed for standard water having a $\mathrm{pH} \sim 7$, buffer

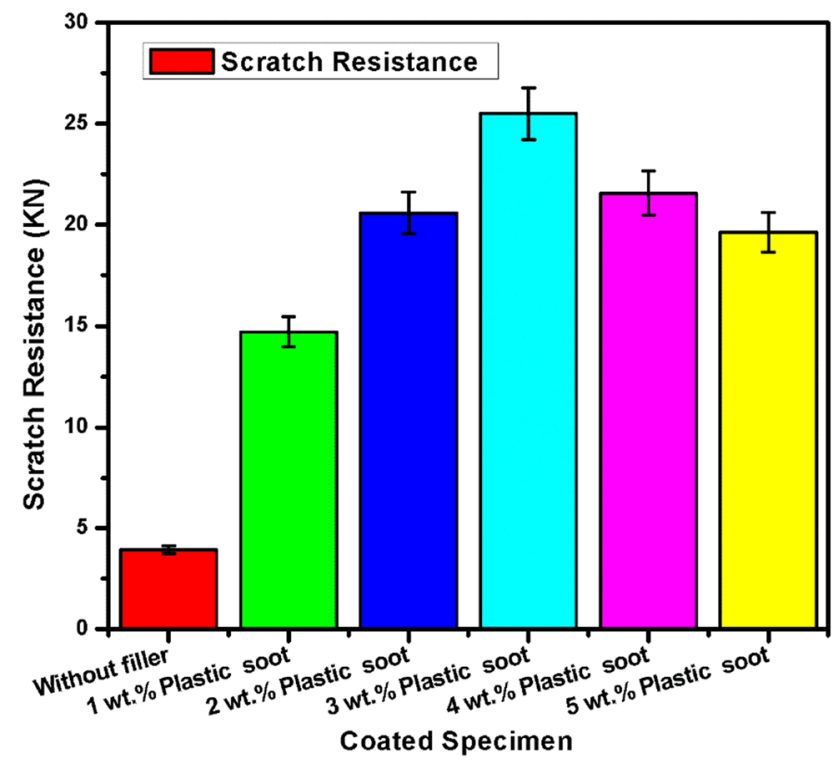

Fig. 5 Scratch resistance of epoxy/carbon soot coated 316L stainless steel substrates

solution of salt-water $(3.55 \% \mathrm{NaCl})$, and an acidic medium having a $\mathrm{pH} \sim 1(0.1 \mathrm{M} \mathrm{HCl}+3.55 \% \mathrm{NaCl})$ [69]. The coated $316 \mathrm{~L}$ substrates demonstrated stability on exposure to alkali solutions (water and salt-water) for over 30 days. However, on exposure to an acidic medium $(\mathrm{pH} \sim 1)$, the coated substrates demonstrated stability on initial exposure, but after exposure of over 10 days, it showed peelingoff of the coatings (Table 2). The improvement in the barrier properties of the epoxy/carbon soot coated substrates in comparison with the pristine epoxy coated substrates is attributed to the reduction in the porosity, most probably due to the incorporation of carbon soot which improved the packing density of the coatings [70]. Considering the

Table 2 Physio-mechanical and chemical characteristics of fabricated coated substrates

\begin{tabular}{|c|c|c|c|c|c|c|}
\hline \multirow{3}{*}{$\begin{array}{l}\text { Carbon soot } \\
\text { loading } \\
(w t \%)\end{array}$} & \multirow{3}{*}{$\begin{array}{l}\text { Scratch test }(\mathrm{kN}) \\
\text { [max. withstand } \\
\text { weight] }\end{array}$} & \multirow{2}{*}{\multicolumn{2}{|c|}{$\frac{\text { Solvent rub test }}{\text { Methyl ethyl ketone }}$}} & \multicolumn{3}{|l|}{ Corrosion resistance test } \\
\hline & & & & \multirow{2}{*}{$\begin{array}{l}\text { Normal water }(\mathrm{pH}=7) \\
\text { After } 30 \text { days }\end{array}$} & \multirow{2}{*}{$\begin{array}{l}\text { Salt water }(\mathrm{pH}=8) \\
\text { After } 20 \text { days }\end{array}$} & \multirow{2}{*}{$\begin{array}{l}0.1 \mathrm{M} \\
\mathrm{HCl}+3.55 \% \\
\mathrm{NaCl}(\mathrm{pH}=1) \\
\text { After } 10 \text { days }\end{array}$} \\
\hline & & After 50 rubs & After 100 rubs & & & \\
\hline 0 & 3.924 & $\begin{array}{l}\text { Moderate amount } \\
\text { coating came } \\
\text { out }\end{array}$ & Shows bare sample & Start to peel off & Stable & Peel off \\
\hline 1 & 14.715 & Pass & $\begin{array}{l}\text { Slight amount of } \\
\text { coating came out }\end{array}$ & Start to peel off & Stable & Peel off \\
\hline 2 & 20.601 & Pass & $\begin{array}{l}\text { Slight amount of } \\
\text { coating came out }\end{array}$ & Start to peel off & Stable & Peel off \\
\hline 3 & 25.506 & Pass & Pass & Stable & Stable & $80 \%$ Peel off \\
\hline 4 & 21.582 & Pass & Pass & Start to peel off & Stable & Peel off \\
\hline 5 & 19.628 & Pass & Pass & Stable & Stable & Peel off \\
\hline
\end{tabular}


alkali solution test, epoxy/carbon soot (3 wt\%) coated substrates revealed better stability as compared to other concentrations, which is most probably due to the more stable physical network. However, the exposure of an acidic medium $(\mathrm{pH} \sim 1)$ revealed the poor performance of the developed coatings, which is most probably due to the high polarity of the solvent, which contains highly active $\mathrm{H}^{+}$species which directly react with reactive groups present on the epoxy polymer [71].

In a study on corrosion performance of carbon black particle-based coatings on metallic substrates, GhasemiKahrizsangi et al. reported that the electrons produced from the metallic substrate could travel through the conductive networks into the coating, which causes a reduction in the rate of oxygen reduction at the interface of the substrate coating and further leads to decline the delamination rate. They further stated that the highly active carbon-black particles (similar to carbon soot particles), which exhibit high surface area, enter into the coating during initial cure-reactions and fill the micropores, thereby improving the packing density of the coating, and thus it shows the high corrosion resistance to the chemicals like $\mathrm{NaCl}$ (3 wt\%). Furthermore, they reported that the carbon particles tend to agglomerate due to inherent van der Wall's forces, and electrostatic charges of attraction, which can lead to its poor dispersion into the epoxy polymer matrix. The reduced dispersion leads to increased porosity in the coatings, due to which the transport of mobile ions (present in the corrosive environment, e.g., $\mathrm{H}_{2} \mathrm{O}$ and $\mathrm{Cl}^{-}$) from coating to the metallic substrate becomes easier and thereby reduces the corrosion performance $[72,73]$.

In another study on epoxy/carbon soot coatings, Okonkwo et al. stated that the absence, or the agglomeration of carbon soot particles on higher loading, in the epoxy polymer can create the stress concentration effect which leads to cracking and subsequent failure of the coatings [74].

Tang et al. [75] reported that the agglomeration of carbon nanomaterials, e.g., carbon nanotubes, in the epoxy polymer could lead to the phase separation during curereaction, thereby causing the failure of epoxy/carbon particle composites.

\subsection{Anti-corrosive performance of epoxy/carbon soot coatings}

The anti-corrosive performance of the developed epoxy/ carbon soot coating toward $316 \mathrm{~L}$ steel substrates was studied via salt spray test as per the ASTM B-117 standards with introduced artificial defects on the substrates [71]. Figure 6 depicts the optical images of the pristine $316 \mathrm{~L}$ steel, pristine epoxy coated steel, and epoxy/carbon soot ( $3 \mathrm{wt} \%$ ) coated steel substrates, before and after the salt spray test. Similar images demonstrating the effects of the salt spray test on the other compositions of the epoxy/carbon soot coated substrates are presented in Supporting Information (Figure S1-S4). As per guidelines from the Naval Materials Research Laboratory, DRDO, India, the coated steel substrate specimens were exposed to corrosive environments for a total period of 20 days. The uncoated steel specimen and the pure epoxy coated steel specimen reveal large corroded areas upon the surface, particularly closer to the scratches.

The pristine epoxy coated steel substrate undergoes delamination across the scribe, designating poor adhesion toward the $316 \mathrm{~L}$ steel substrate. Epoxy/carbon soot coated samples reveal improved performance, with the corrosion inhibition characteristic enhancing with the increased filler loading of carbon soot particles in the epoxy matrix [Supporting Information (Figure S1-S4)]. A small quantity of white-colored rusting appears inside the scratches of the epoxy/carbon soot coated steel specimens, which is attributed to the reactive ions present in the $\mathrm{NaCl}$ salt, which reacts with the surface of the metal $[76,77]$. Results establish that the developed epoxy/carbon soot coatings can effectively resist the existence and breeding of localized corrosion on the exposure of aggressive corrosive environments.

Similarly, the corrosion performance of epoxy/carbon soot coatings was evaluated using polarization curves, i.e., Tafel plots (Fig. 7) [1]. During the experiment, the open circuit potential of all specimens was attained after $30 \mathrm{~min}$. Tafel polarization-curves revealed the corrosion potentials $\left(E_{\text {corr }}\right)$ and corrosion current density $\left(I_{\text {corr }}\right)$ calculations of the utilized test specimens (Fig. 7). Thermodynamic corrosion tendency and the effective corrosion rate of coated steel substrates are reflected by a negative shift in the $I_{\text {corr }}$ and a positive shift in $E_{\text {corr }}$ [78].

The rate of corrosion can be quantified via experimentally derived corrosion current density $\left(I_{\text {corr }}\right)$ by utilization of following equation [79]:

$\mathrm{CR}=\frac{I_{\text {corr }} \times \mathrm{EW} \times K}{d}$

where $d$ is density $\left(\mathrm{gm} / \mathrm{cm}^{3}\right)$, EW is the equivalent weight $(\mathrm{gm} / \mathrm{mol})$ and $K$ is constant which terms units for rate of corrosion $\left(3.27 \times 10^{-3} \mathrm{~mm} \mathrm{~g} / \mu \mathrm{A} \mathrm{cm}\right.$ year$)$.

Tafel curves reveal that incorporation of the carbon soot nanoparticles in the epoxy matrix aid in improving the corrosion performance of the coated substrates, which is observed from the decreased corrosion current density $\left(I_{\text {corr }}\right)$, decreased corrosion rate $(\mathrm{gm} / \mathrm{hr})$, and improved corrosion potential $\left(E_{\text {corr }}\right)$ as compared to uncoated and pristine epoxy coated substrates (Table 3 ). 
(a)

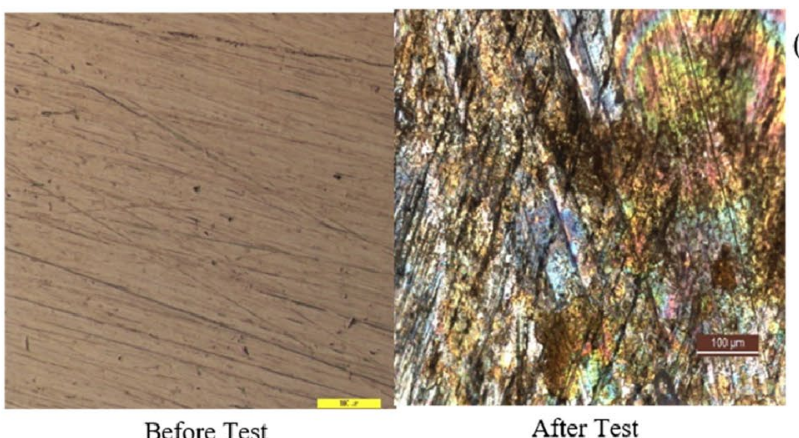

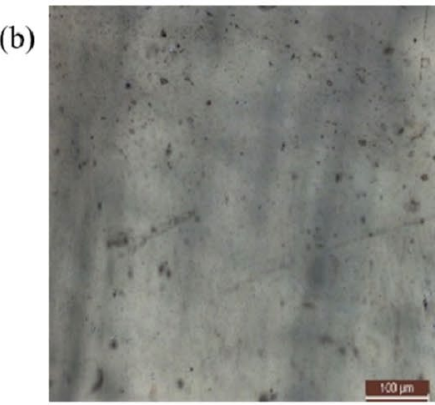

Before Test

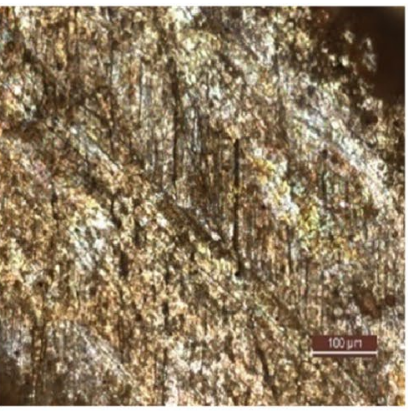

After Test

(c)

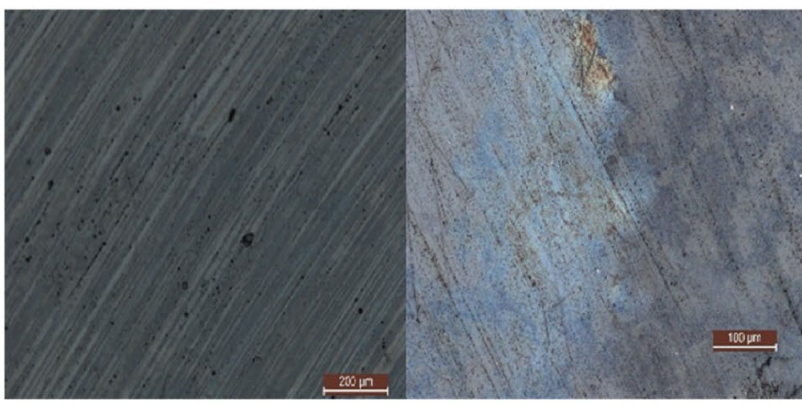

Before Test

After Test

Fig. 6 Optical images of salt spray test for a bare 316L steel substrate; b pure epoxy coated 316L substrate; c Epoxy +3 wt $\%$ plastic carbon soot coated $316 \mathrm{~L}$ steel substrate

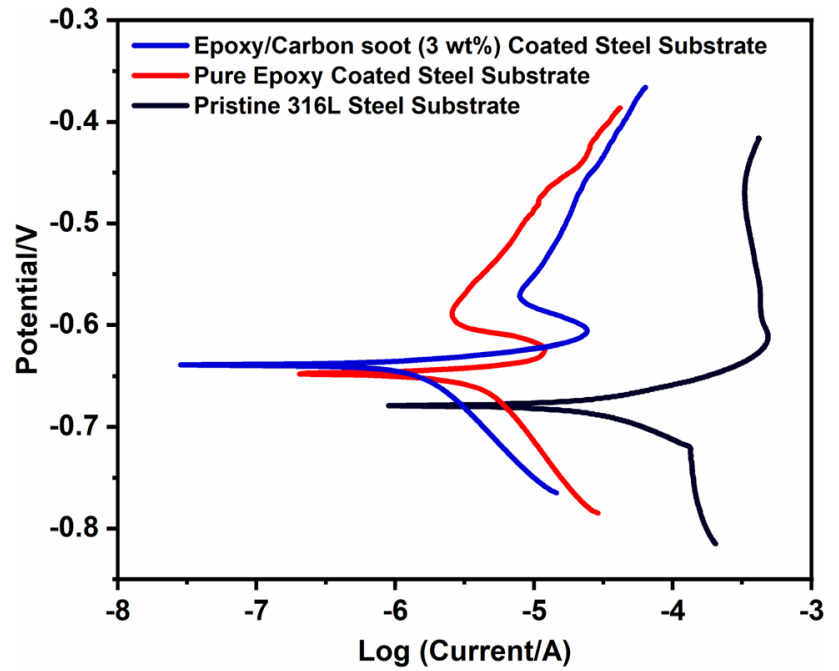

Fig. 7 Tafel polarization curves for: a pristine $316 \mathrm{~L}$ steel substrate (uncoated); b pure epoxy coated 316L substrate; c epoxy/carbon soot ( $3 \mathrm{wt} \%$ ) coated $316 \mathrm{~L}$ steel substrate
Epoxy/carbon soot ( $3 \mathrm{wt} \%$ ) coated substrates demonstrate improved corrosion performance as compared to uncoated and pristine epoxy coated substrates due to lower $I_{\text {corr }}$ values which indicate the barrier effect.

Ghasemi-Kahrizsangi et al. reported that the diffusion of the reactive ions (from $\mathrm{NaCl}$ ) and water on the steel substrate and coating interface (in this case, uncoated and pristine epoxy coated steel substrate) gets accelerated due to corrosion reactions, which eventually leads to poor corrosion performance. Further, they stated that the incorporation of carbon particles (in the present case, carbon soot particles) creates a barrier network that restricts the diffusion of the $\mathrm{NaCl}$ and water to the steel substrate. These carbon particles, when added into the epoxy matrix, fill the micropores generated during curing reactions (in this case, pristine cured epoxy), and simultaneously form barrier network of the carbon particles, thereby aiding in restricting the diffusion of the corrosive liquid into the steel substrate [72].
Table 3 Corrosion current density, corrosion potential, and the rate of corrosion results

\begin{tabular}{llll}
\hline Specimens & $E_{\text {corr }}(\mathrm{V})$ & $I_{\text {corr }}\left(\mathrm{A} \mathrm{m}^{-2}\right)$ & Corrosion rate $\left(\mathrm{g} \mathrm{h}^{-1}\right)$ \\
\hline Pristine 316L steel (uncoated) & -0.681 & $5.871 \times \mathrm{e}^{-4}$ & $6.189 \times \mathrm{e}^{-4}$ \\
Pristine epoxy coated 316L steel & -0.651 & $1.742 \times \mathrm{e}^{-5}$ & $1.809 \times \mathrm{e}^{-5}$ \\
$\begin{array}{l}\text { Epoxy/carbon soot (3 wt\%) coated 316L } \\
\text { steel }\end{array}$ & -0.578 & $2.942 \times \mathrm{e}^{-6}$ & $3.096 \times \mathrm{e}^{-6}$ \\
\hline
\end{tabular}


Okonkwo et al. reported that the carbon soot particles exhibit amorphous and graphitic structures along with the small amount of non-graphitic phase, which is arranged in short order range, and, thus, on higher loading, it helps in giving reinforcing strength, and improved corrosion performance to epoxy/carbon soot coatings [74].

The improved carrion performance of the epoxy/ carbon soot ( $3 \mathrm{wt} \%$ ) coatings is attributed to various factors. Among them, one of the factors is an epoxy matrix, which is a thermoset polymer, which itself acts as an insulating layer due to its non-conductive, insulating nature with high dielectric strength. Upon curing with the hardener, the liquid phase epoxy polymer gets solidified, where it becomes more insulating due to the cross-linking of the polymeric segments $[11,13,80]$. Further, a 3 wt\% loading of carbon soot particles in the epoxy matrix probably fills the micropores and increases the chain packing density of the cured epoxy/carbon soot coatings, thereby restricting the current through the coating layer. The literature states that carbon soot particles possess an amorphous phase, graphitic phase, and small amount of non-graphitic phase, which are ordered in short-ranged order and also possess conductive nature and exhibit a cathodic tendency toward metals like $316 \mathrm{~L}$ stainless steel. It has been reported in various literature that a $3 \mathrm{wt} \%$ loading of nano-sized carbon particles disperses in the epoxy matrix, which creates reinforcing network, filling of micropores, and improves the chain packing density [75]. However, a 3 $\mathrm{wt} \%$ loading of the nano-carbon particles in the epoxy matrix also leads to the formation of the clusters, which disperse randomly and facilitates a well-established network, but with a non-continuous conducting phase, and cluster formation, i.e., agglomeration, which eventually leads to restricted conductivity to free ions from the corrosive environment [72-74]. This fact is supported by the lower corrosion current density $\left(2.942 \times \mathrm{e}^{-6} \mathrm{~A} / \mathrm{m}^{2}\right)$, higher corrosion potential $(-0.578 \mathrm{~V})$, and the lower corrosion rate $\left(3.096 \times \mathrm{e}^{-6} \mathrm{gm} / \mathrm{h}\right)$ of the epoxy/carbon soot (3 wt\%) coatings as compared to uncoated and pristine epoxy coated $316 \mathrm{~L}$ substrates. Although the carbon soot particles toward 316 Ltainless steel possess the conductive nature and cathodic tendency, its reactivity to steel and risk to cause the failure of the epoxy/carbon soot coatings is nullified by the inherent non-conductive and highly insulating nature, along with high dielectric strength of the cured thermoset epoxy polymer [72-74].

Thus, it can be concluded that it is safe to use epoxy/ carbon soot coatings for its utilization as a protective corrosion-resistant coating for $316 \mathrm{~L}$ substrates in marine environments.

\subsection{Theoretical aspects of the processing parameters affecting the fluid atomization}

Air-supported fluid atomizer exhibiting lower volume and higher force spray-gun was utilized for preparing the coating on surface engineered steel substrates demonstrated symmetric full-cone spray kind patternation, as it directly influences surface attributes of the deposited coating [81, 82].

Researchers have validated that the nozzle dimensions and quality utilized during the spray atomization coating process play a significant role in governing the pattern symmetry that could be impaired via eccentric alignment, poor surface finish, or orifice imperfections [83]. A crucial part during the drying of the coated surface design is played by the droplet surface area, which can be tuned via precise patternation [1]. Design of atomizer orifice and its internal geometry aids in achieving the control over mass flux rate by validating contours of spray boundary and distribution of droplets [81]. In the present study, full-cone type patternation, as depicted in Fig. 8 , has been used for developing the protective anti-corrosive coating of homogenous thickness across the complete cross-section of the substrate.

Air pressure applied via connected compressor during the atomization process governs the total volume flux rate of epoxy/carbon soot nanoparticle dispersion. The capacity of the nozzle at varying pressures can be determined by using the following equation:

$Q_{2}=Q_{1} \times \sqrt{\frac{P_{2}}{P_{1}}}$

where $Q_{2}=$ capacity of spray-nozzle at pressure $P_{2}$, $Q_{1}=$ capacity of spray-nozzle at pressure $P_{1}$, and $P_{1}$ and $P_{2}=$ air pressures at different instances.

Equation stated above determines the growing influence of air pressure upon augmenting the capacity of the nozzle, which successively improves efficiency, thus suggesting the greater air-pressures for a higher flow rate through the nozzle for reducing time for spray coating [1]. The inverse effect of increasing injection pressure results in decreasing of Sauter Mean Diameter (SMD) of introduced dispersion cause of greater atomization force accessible at superior pressures was demonstrated successfully by Elkotb et al. [84]. Similarly, contrary interrelation among SMD and pressure for nozzle configurations were also validated by Hiroyasu and Kadota [85] in their investigation. They reported that the increase in air pressure demonstrates a synergistic effect upon volume flux rate yielding higher efficiency and SMD yielding smaller drops additional to atomization. 
Fig. 8 Classes of patternation: a full cone, $\mathbf{b}$ hollow cone, and c flat fan

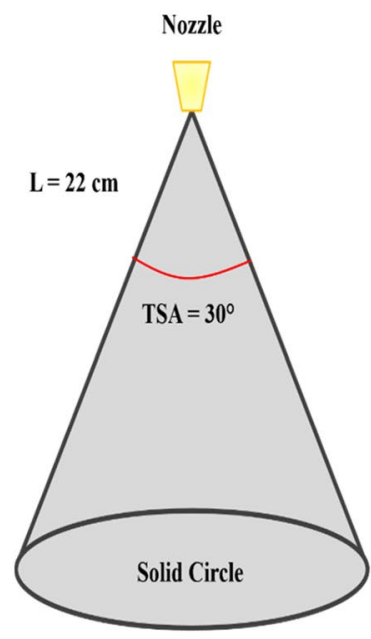

(a)

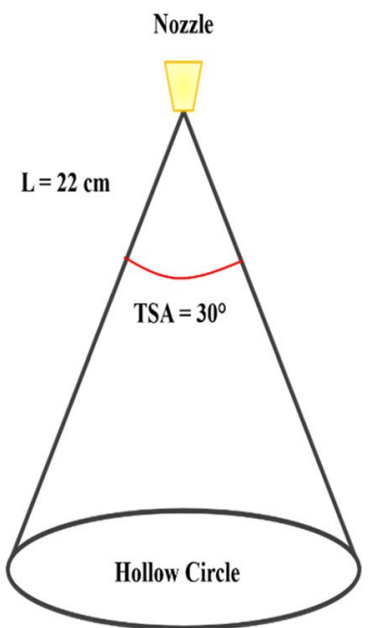

(b)

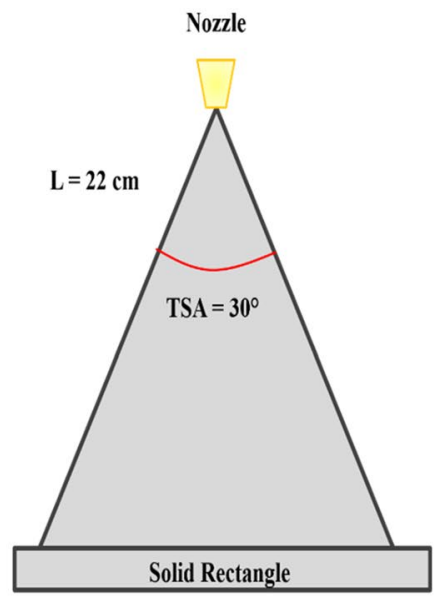

(c)

For the buildup of the micron-sized thick coating during the conducted investigation, air-pressure-aided externally coupled two-fluid atomizer, i.e., epoxy/carbon soot nanoparticle dispersal and compressed air were utilized. At the same time, the volume flux rate was $\sim 0.2$ $\mathrm{ml} / \mathrm{s}$ equivalent to 3-bar pressure and was calculated from a nozzle that ensured a higher sedimentation rate throughout the coating procedure [86]. The effect on surface roughness is demonstrated by the applied air pressure during the spray coating process. Perfetti et al. [87] during their investigation demonstrated positive influence upon surface roughness during intensification in pressure, whereas in another investigation Xingzhong et al. [88] revealed that a decrease in pressure yields in an even and constant coating. Therefore for avoiding positive as well as the negative influence of air pressure upon surface roughness, an augmented air pressure of 3-bar was consistently maintained during our investigation.

The opening angle produced precisely close to nozzle-jet via drops arising from atomizer is termed as a spray cone angle. Even though for a specific atomizer, the spray cone angle is predefined; however, it could be affected by external parameters like air drag and gravitational forces $[82,89]$. Figure 9 illustrates the schematic of spray angle and spray coverage produced during spray atomization, while trigonometric relation among TSA and TSC is given by the following equation:

$\mathrm{TSC}=2 \times L \times \tan \left(\frac{\mathrm{TSA}}{2}\right)$

where $L$ is the distance; TSA and ASA are theoretical spray angle and actual spray angle, respectively, and TSC and ASC are theoretical spray coverage and actual spray coverage correspondingly.

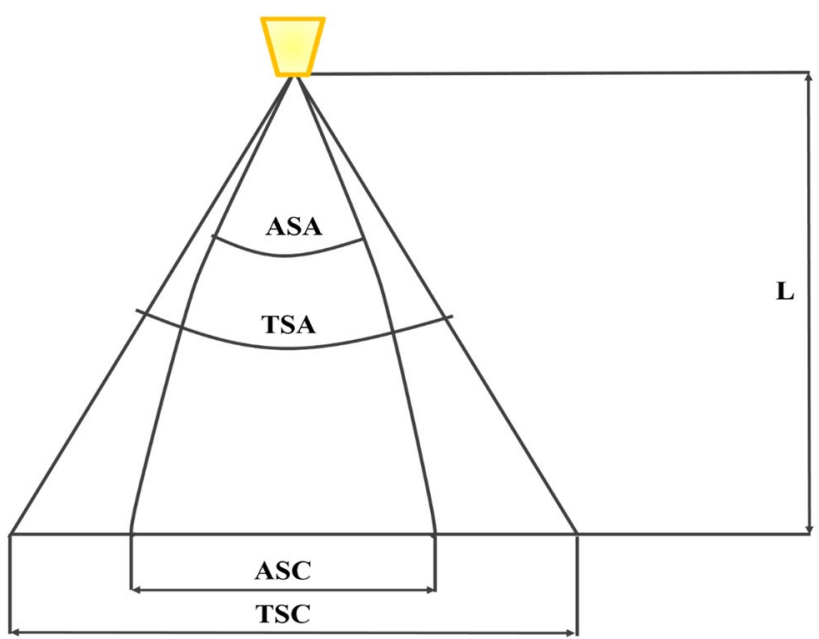

Fig. 9 Schematic illustration of theoretical spray angle and theoretical spray

Determination of TSA by utilization of the above equation and ignoring the interference of external parameters in the fabricated protective anti-corrosive coating system was elucidated to be around $30^{\circ}$. Corresponding TSC for a narrow spray angle $\left(30^{\circ}\right)$ via hand spray gun is $13-15 \mathrm{~cm}$ determined at a spraying length of $22 \mathrm{~cm}$ [1]. Calculated narrow spray angle ensures adequate coverage evading non-coated sections throughout hand-spray coating and also manifests avoidance of over-spraying from the target sample. Combination of the formation of worthy value liquid-film produced via spray coating methodology and its subsequent thermal therapy utilized for drying liquid coating consequences in a higher class reliable dry-coated product. 


\section{Conclusion}

In summary, an anti-corrosion resistant protective coating based on epoxy and carbon soot particles (derived from waste polyolefin-based plastic) is developed with the aid of pneumatic fluid atomization technique. The epoxy/ carbon soot coating with a filler loading of $3 \mathrm{wt} \%$ yielded an enhanced anti-corrosion performance. The formation of carbon soot nanoparticles was confirmed via Raman spectroscopy and FE-SEM analysis, which established that the dimensions for the carbon soot particles are in the range of $\sim 41-62 \mathrm{~nm}$. Physio-mechanical and chemical performance analysis of the epoxy/carbon soot coated substrates indicates that the $3 \mathrm{wt} \%$ loading of carbon soot nanoparticles enhances the adhesion and solvent-resistance of the coated steel substrates. Furthermore, the anticorrosion performance of the epoxy/carbon soot coatings was evaluated using polarization Tafel curves revealed the enhanced anti-corrosion performance of epoxy/carbon soot (3 wt\%) coatings, where the corrosion current density $\left(2.942 \times \mathrm{e}^{-6} \mathrm{~A} / \mathrm{m}^{2}\right)$, corrosion rate $\left(3.096 \times \mathrm{e}^{-6} \mathrm{gm} / \mathrm{h}\right)$ were found to be decreased. The successive results indicate that the epoxy/carbon soot ( 3 wt\%) coatings can be potentially used for the corrosion inhibition of the $3016 \mathrm{~L}$ stainless steel substrated for short-term underwater marine applications.

Acknowledgements The authors are thankful to Dr. C. P. Ramanarayanan, Vice-Chancellor of DIAT (DU), Pune, for constant encouragement and support. The authors acknowledge Mr. Swaroop Gharde and Mr. RaviPrakash Magisetty for technical discussions and support. The authors are thankful to all anonymous reviewers and the Editor for improving the quality of the revised manuscript by their valuable comments and suggestions.

\section{Compliance with ethical standards}

Conflict of interest The authors do not have any conflicts of interest.

\section{References}

1. Bangar GY, Ghule D, Singh RKP, Kandasubramanian B (2018) Thermally triggered transition of fluid atomized micro- and nanotextured multiscale rough surfaces. Colloids Surf A Physicochem Eng Asp 549:212-220. https://doi.org/10.1016/j.colsu rfa.2018.03.044

2. Badhe Y, Balasubramanian K (2014) Novel hybrid ablative composites of resorcinol formaldehyde as thermal protection systems for re-entry vehicles. RSC Adv 4:28956-28963. https://doi. org/10.1039/c4ra03316g

3. Fontana MG (2005) Corrosion engineering. Tata Mcgraw-Hill Education, New York

4. Wang D, Bierwagen GP (2009) Sol-gel coatings on metals for corrosion protection. Prog Organ Coat 64:327-338. https://doi. org/10.1016/j.porgcoat.2008.08.010
5. Chatterjee U, Bose SK, Roy SK (2001) Environmental degradation of metals: corrosion technology series/14. CRC Press Inc, New York

6. Ejenstam L, Ovaskainen L, Rodriguez-Meizoso I et al (2013) The effect of superhydrophobic wetting state on corrosion protection-the AKD example. J Colloid Interface Sci 412:56-64. https ://doi.org/10.1016/j.jcis.2013.09.006

7. Abdollahi H, Ershad-langroudi A, Salimi A, Rahimi A (2014) Anticorrosive coatings prepared using epoxy-silica hybrid nanocomposite materials. Corros Sci 123:21-26

8. Uhlig HH (1950) The cost of corrosion to the United States. Corrosion 6:29-33. https://doi.org/10.5006/0010-9312-6.1.29

9. Biezma MV, San Cristóbal JR (2005) Methodology to study cost of corrosion. Corros Eng Sci Technol 40:344-352. https://doi. org/10.1179/174327805X75821

10. Wei H, Ding D, Wei S, Guo Z (2013) Anticorrosive conductive polyurethane multiwalled carbon nanotube nanocomposites. J Mater Chem A 1:10805. https://doi.org/10.1039/c3ta11966a

11. Echeverría M, Abreu CM, Lau K, Echeverría CA (2016) Viability of epoxy-siloxane hybrid coatings for preventing steel corrosion. Prog Organ Coat 92:29-43. https://doi.org/10.1016/j.porgc oat.2015.12.005

12. Haddadi SA, Mahdavian M, Karimi E (2015) Evaluation of the corrosion protection properties of an epoxy coating containing sol-gel surface modified nano-zirconia on mild steel. RSC Adv 5:28769-28777. https://doi.org/10.1039/C5RA02127H

13. Ramezanzadeh B, Niroumandrad S, Ahmadi A et al (2016) Enhancement of barrier and corrosion protection performance of an epoxy coating through wet transfer of amino functionalized graphene oxide. Corros Sci 103:283-304. https://doi. org/10.1016/j.corsci.2015.11.033

14. Chang $\mathrm{C}-\mathrm{H}$, Huang $\mathrm{T}-\mathrm{C}$, Peng $\mathrm{C}-\mathrm{W}$ et al (2012) Novel anticorrosion coatings prepared from polyaniline/graphene composites. Carbon N Y 50:5044-5051. https://doi.org/10.1016/j.carbo n.2012.06.043

15. Alamri H, Low IM (2012) Effect of water absorption on the mechanical properties of nano-filler reinforced epoxy nanocomposites. Mater Des 42:214-222. https://doi.org/10.1016/j. matdes.2012.05.060

16. Shi H, Liu F, Yang L, Han E (2008) Characterization of protective performance of epoxy reinforced with nanometer-sized $\mathrm{TiO}_{2}$ and $\mathrm{SiO}_{2}$. Prog Organ Coat 62:359-368. https://doi. org/10.1016/j.porgcoat.2007.11.003

17. Shi X, Nguyen TA, Suo Z et al (2009) Effect of nanoparticles on the anticorrosion and mechanical properties of epoxy coating. Surf Coat Technol 204:237-245. https://doi.org/10.1016/j.surfc oat.2009.06.048

18. Sørensen PA, Kiil S, Dam-Johansen K, Weinell CE (2009) Anticorrosive coatings: a review. J Coat Technol Res 6:135-176. https:// doi.org/10.1007/s11998-008-9144-2

19. Ji W-G, Hu J-M, Zhang J-Q, Cao C-N (2006) Reducing the water absorption in epoxy coatings by silane monomer incorporation. Corros Sci 48:3731-3739. https://doi.org/10.1016/j.corsc i.2006.02.005

20. Ramezanzadeh B, Attar MM (2011) Studying the corrosion resistance and hydrolytic degradation of an epoxy coating containing ZnO nanoparticles. Mater Chem Phys 130:1208-1219. https:// doi.org/10.1016/j.matchemphys.2011.08.065

21. Nematollahi M, Heidarian M, Peikari M et al (2010) Comparison between the effect of nanoglass flake and montmorillonite organoclay on corrosion performance of epoxy coating. Corros Sci 52:1809-1817. https://doi.org/10.1016/j.corsci.2010.01.024

22. Behzadnasab M, Mirabedini SM, Kabiri K, Jamali S (2011) Corrosion performance of epoxy coatings containing silane treated $\mathrm{ZrO}_{2}$ nanoparticles on mild steel in $3.5 \% \mathrm{NaCl}$ solution. Corros Sci 53:89-98. https://doi.org/10.1016/j.corsci.2010.09.026 
23. Chen L, Chai S, Liu K et al (2012) Enhanced epoxy/silica composites mechanical properties by introducing graphene oxide to the interface. ACS Appl Mater Interfaces 4:4398-4404. https ://doi.org/10.1021/am3010576

24. Ma Y, Di H, Yu Z et al (2016) Fabrication of silica-decorated graphene oxide nanohybrids and the properties of composite epoxy coatings research. Appl Surf Sci 360:936-945. https:// doi.org/10.1016/j.apsusc.2015.11.088

25. Nazal MK, Mazumder MAJ (2018) Anticorrosive Coating. In: Mazumder MAJ, Sheardown H, Al-Ahmed A (eds) Functional Polymers, 1st ed. Springer, Cham, pp 1-27. https://doi. org/10.1007/978-3-319-92067-2_24-1

26. Ding J, Rahman O, Wang Q et al (2017) Sustainable graphene suspensions: a reactive diluent for epoxy composite valorization. ACS Sustain Chem Eng 5:7792-7799. https://doi. org/10.1021/acssuschemeng.7b01282

27. Nowack B, David RM, Fissan H et al (2013) Potential release scenarios for carbon nanotubes used in composites. Environ Int 59:1-11. https://doi.org/10.1016/j.envint.2013.04.003

28. Bazargan A, McKay G (2012) A review-synthesis of carbon nanotubes from plastic wastes. Chem Eng J 195-196:377-391. https://doi.org/10.1016/j.cej.2012.03.077

29. Korde JM, Shaikh M, Kandasubramanian B (2018) Bionic prototyping of honeycomb patterned polymer composite and its engineering application. Polym Plast Technol Eng. https://doi. org/10.1080/03602559.2018.1434667

30. Deng J, You Y, Sahajwalla V, Joshi RK (2016) Transforming waste into carbon-based nanomaterials. Carbon NY 96:105-115. https ://doi.org/10.1016/j.carbon.2015.09.033

31. Korde JM, Kandasubramanian B (2018) Biocompatible alkyl cyanoacrylates and their derivatives as bio-adhesives. Biomater Sci 6:1691-1711. https://doi.org/10.1039/c8bm00312b

32. Zhuo C, Levendis YA (2014) Upcycling waste plastics into carbon nanomaterials: a review. J Appl Polym Sci 131:1-14. https://doi. org/10.1002/app.39931

33. Zhao X, Liu S, Wang X, Hou B (2014) Surface modification of $\mathrm{ZrO}_{2}$ nanoparticles with styrene coupling agent and its effect on the corrosion behaviour of epoxy coating. Chin J Oceanol Limnol 32:1163-1171. https://doi.org/10.1007/s00343-014-3327-8

34. Korde JM, Kandasubramanian B (2019) Fundamentals and effects of biomimicking stimuli-responsive polymers for engineering functions. Ind Eng Chem Res 58:9709-9757. https://doi. org/10.1021/acs.iecr.9b00683

35. Manjumeena R, Venkatesan R, Duraibabu D et al (2016) Green nanosilver as reinforcing eco-friendly additive to epoxy coating for augmented anticorrosive and antimicrobial behavior. Silicon 8:277-298. https://doi.org/10.1007/s12633-015-9327-2

36. Lam CK, Lau KT (2006) Localized elastic modulus distribution of nanoclay/epoxy composites by using nanoindentation. Compos Struct 75:553-558. https://doi.org/10.1016/j.compstruct 2006.04.045

37. Hartwig A, Sebald M, Pütz D, Aberle L (2005) Preparation, characterisation and properties of nanocomposites based on epoxy resins-an overview. Macromol Symp 221:127-136. https://doi. org/10.1002/masy.200550313

38. Tang $Y$, Ye L (2015) Nanosilica-reinforced epoxy composites for marine applications. In: Dong Y, Umer R, Lau AK-T (eds) Fillers and reinforcements for advanced nanocomposites, 1 st ed. Elsevier, Amsterdam, pp 425-459. https://doi.org/10.1016/B978-008-100079-3.00017-X

39. Chen C, Qiu S, Cui M et al (2017) Achieving high performance corrosion and wear resistant epoxy coatings via incorporation of noncovalent functionalized graphene. Carbon NY 114:356-366. https://doi.org/10.1016/j.carbon.2016.12.044

40. Gu L, Liu S, Zhao H, Yu H (2015) Facile preparation of waterdispersible graphene sheets stabilized by carboxylated oligoanilines and their anticorrosion coatings. ACS Appl Mater Interfaces 7:17641-17648. https://doi.org/10.1021/acsam i.5b05531

41. Thakur A, Gharde S, Kandasubramanian B (2019) Electroless nickel fabrication on surface modified magnesium substrates. Def Technol. https://doi.org/10.1016/j.dt.2019.04.006

42. Prajapati DG, Kandasubramanian B (2019) Biodegradable polymeric solid framework-based organic phase-change materials for thermal energy storage. Ind Eng Chem Res. https://doi. org/10.1021/acs.iecr.9b01693

43. Magisetty R, Shukla A, Kandasubramanian B (2019) Terpolymer

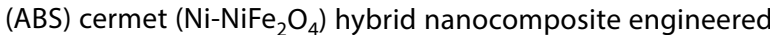
3D-carbon fabric mat as a X-band electromagnetic interference shielding material. Mater Lett 238:214-217. https://doi. org/10.1016/J.MATLET.2018.12.023

44. Saini S, Kandasubramanian B (2018) Engineered smart textiles and janus microparticles for diverse functional industrial applications. Polym Plast Technol Eng. https://doi.org/10.1080/03602 559.2018.1466177

45. Gore PM, Kandasubramanian B (2018) Heterogeneous wettable cotton based superhydrophobic Janus biofabric engineered with PLA/functionalized-organoclay microfibers for efficient oil-water separation. J Mater Chem A 6:7457-7479. https://doi. org/10.1039/C7TA11260B

46. Gudivada G, Kandasubramanian B (2019) Zirconium-doped hybrid composite systems for ultrahigh-temperature oxidation applications: a review. Ind Eng Chem Res 58:4711-4731. https ://doi.org/10.1021/acs.iecr.8b05586

47. Yadav R, Tirumali M, Wang X et al (2019) Polymer composite for antistatic application in aerospace. Def Technol. https://doi. org/10.1016/j.dt.2019.04.008

48. Yadav R, Balasubramanian K (2015) Polyacrylonitrile/syzygium aromaticum hierarchical hydrophilic nanocomposite as a carrier for antibacterial drug delivery systems. RSC Adv 5:3291-3298. https://doi.org/10.1039/c4ra12755b

49. Kumar V, Balasubramanian K (2016) Progress update on failure mechanisms of advanced thermal barrier coatings: a review. Prog Organ Coat 90:54-82. https://doi.org/10.1016/j.porgc oat.2015.09.019

50. Kumar V, Kandasubramanian B (2016) Processing and design methodologies for advanced and novel thermal barrier coatings for engineering applications. Particuology 27:1-28. https://doi. org/10.1016/j.partic.2016.01.007

51. Gharde S, Surendren A, Korde JM et al (2019) Recent advances in additive manufacturing of bio-inspired materials. In: Prakash $C$ et al (eds) Biomanufacturing. Springer International Publishing, Cham, pp 35-68

52. Gharde S, Kandasubramanian B (2018) The importance of electroless metallic build-up on surface modified substrates for multifunctional engineering applications: a recent progress update. Trans Indian Inst Met. https://doi.org/10.1007/s1266 6-018-1397-6

53. Bolleddula DA, Berchielli A, Aliseda A (2010) Impact of a heterogeneous liquid droplet on a dry surface: application to the pharmaceutical industry. Adv Colloid Interface Sci 159:144-159. https://doi.org/10.1016/j.cis.2010.06.003

54. Wu YL, Chen Z, Zeng XT (2008) Nanoscale morphology for high hydrophobicity of a hard sol-gel thin film. Appl Surf Sci 254:6952-6958. https://doi.org/10.1016/j.apsusc.2008.05.002

55. Yadav R, Zachariah S, Balasubramanian K (2016) Thermally stable transparent hydrophobic bio-mimetic dual scale spherulites coating by spray deposition. Adv Sci Eng Med 8:181-187. https ://doi.org/10.1166/asem.2016.1842

56. Banerjee BS, Balasubramanian K (2015) Nanotexturing of $P C / n-$ HA nanocomposites by innovative and advanced spray system. RSC Adv 5:13653-13659. https://doi.org/10.1039/c4ra15488f 
57. Gore PM, Balakrishnan S, Kandasubramanian B (2019) Superhydrophobic corrosion inhibition polymer coatings. Superhydrophobic Polym Coat. https://doi.org/10.1016/B978-0-12-81667 1-0.00011-4

58. Sahoo BN, Kandasubramanian B (2014) Photoluminescent carbon soot particles derived from controlled combustion of camphor for superhydrophobic applications. RSC Adv 4:1133111342. https://doi.org/10.1039/c3ra46193a

59. Simon S, Balasubramanian K (2018) Facile immobilization of camphor soot on electrospun hydrophobic membrane for oil-water separation. Mater Focus 7:295-303. https://doi. org/10.1166/mat.2018.1511

60. Simon S, Malik A, Kandasubramanian B (2018) Hierarchical electrospun super-hydrophobic nanocomposites of fluoroelastomer. Mater Focus 7:194-206. https://doi.org/10.1166/ mat.2018.1499

61. Sahoo BN, Balasubramanian K, Sucheendran M (2015) Thermally triggered transition of superhydrophobic characteristics of micro- and nanotextured multiscale rough surfaces. J Phys Chem C. https://doi.org/10.1021/acs.jpcc.5b02917

62. Sahoo BN, Balasubramanian K (2015) A nanocellular PVDFgraphite water-repellent composite coating. RSC Adv 5:67436751. https://doi.org/10.1039/C4RA06704E

63. Sahoo BN, Kandasubramanian B, Thomas A (2013) Effect of $\mathrm{TiO}_{2}$ powder on the surface morphology of micro/nanoporous structured hydrophobic fluoropolymer based composite material. J Polym 2013:1-4. https://doi.org/10.1155/2013/615045

64. Sahoo BN, Kandasubramanian B (2014) An experimental design for the investigation of water repellent property of candle soot particles. Mater Chem Phys 148:134-142. https://doi. org/10.1016/j.matchemphys.2014.07.022

65. Dixon Dikio E (2011) Morphological characterization of soot from the atmospheric combustion of diesel fuel. Int J Electrochem Sci 6:2214-2222

66. Kumar M, Ando Y (2005) Controlling the diameter distribution of carbon nanotubes grown from camphor on a zeolite support. Carbon N Y 43:533-540. https://doi.org/10.1016/j.carbo n.2004.10.014

67. Krupička A, Johansson M, Hult A (2003) Use and interpretation of scratch tests on ductile polymer coatings. Prog Organ Coat 46:32-48. https://doi.org/10.1016/S0300-9440(02)00184-4

68. Wang Y, Lim S, Luo JL, Xu ZH (2006) Tribological and corrosion behaviors of $\mathrm{Al}_{2} \mathrm{O}_{3}$ /polymer nanocomposite coatings. Wear 260:976-983. https://doi.org/10.1016/j.wear.2005.06.013

69. Ismail EA, Motawie AM, Sadek EM (2011) Synthesis and characterization of polyurethane coatings based on soybean oilpolyester polyols. Egypt J Pet 20:1-8. https://doi.org/10.1016/j. ejpe.2011.06.009

70. Melchiors M, Sonntag M, Kobusch C, Jürgens E (2000) Recent developments in aqueous two-component polyurethane (2K-PUR) coatings. Prog Organ Coat 40:99-109. https://doi. org/10.1016/S0300-9440(00)00123-5

71. Velayutham TS, Majid WHA, Ahmad AB et al (2009) Synthesis and characterization of polyurethane coatings derived from polyols synthesized with glycerol, phthalic anhydride and oleic acid. Prog Organ Coat 66:367-371. https://doi.org/10.1016/j.porgc oat.2009.08.013

72. Ghasemi-Kahrizsangi A, Shariatpanahi $H$, Neshati J, Akbarinezhad E (2015) Corrosion behavior of modified nano carbon black/epoxy coating in accelerated conditions. Appl Surf Sci 331:115-126. https://doi.org/10.1016/j.apsusc.2015.01.038

73. Wei YH, Zhang LX, Ke W (2007) Evaluation of corrosion protection of carbon black filled fusion-bonded epoxy coatings on mild steel during exposure to a quiescent $3 \% \mathrm{NaCl}$ solution. Corros Sci 49:287-302. https://doi.org/10.1016/j.corsci.2006.06.018
74. Okonkwo AO, Jagadale P, García Herrera JE et al (2015) Hightoughness/low-friction ductile epoxy coatings reinforced with carbon nanostructures. Polym Test 47:113-119. https://doi. org/10.1016/j.polymertesting.2015.09.001

75. Tang L-C, Wan Y-J, Peng K et al (2013) Fracture toughness and electrical conductivity of epoxy composites filled with carbon nanotubes and spherical particles. Compos A Appl Sci Manuf 45:95-101. https://doi.org/10.1016/j.compositesa.2012.09.012

76. Nishimura T (2015) Nano structure of the rust formed on chromium bearing steel in concrete after wet and dry corrosion test. ISIJ Int 55:1739-1746. https://doi.org/10.2355/isijinternation al.ISIJINT-2015-055

77. Raj XJ (2017) Application of EIS and SECM studies for investigation of anticorrosion properties of epoxy coatings containing zinc oxide nanoparticles on mild steel in $3.5 \% \mathrm{NaCl}$ solution. J Mater Eng Perform 26:3245-3253. https://doi.org/10.1007/ s11665-017-2770-z

78. Vengatesh P, Kulandainathan MA (2015) Hierarchically ordered self-lubricating superhydrophobic anodized aluminum surfaces with enhanced corrosion resistance. ACS Appl Mater Interfaces 7:1516-1526. https://doi.org/10.1021/am506568v

79. ASTM (1999) Standard practice for calculation of corrosion rates and related information from electrochemical measurements. ASTM G102-89 89:1-7. https://doi.org/10.1520/G0102-89R15 E01

80. Fröhlich J, Thomann R, Mülhaupt R (2003) Toughened epoxy hybrid nanocomposites containing both an organophilic layered silicate filler and a compatibilized liquid rubber. Macromolecules 36:7205-7211. https://doi.org/10.1021/ma035004d

81. Nasr GG, Yule AJ, Bendig L (2002) Background on sprays and their production. Industrial sprays and atomization. Springer, London, pp 7-33

82. Lefebvre AH (1989) Properties of sprays. Part Part Syst Charact 6:176-186. https://doi.org/10.1002/ppsc.19890060129

83. Tate RW (1960) Equipment and design—spray patternation. Ind Eng Chem 52:49A-58A. https://doi.org/10.1021/ie50610a005

84. Elkotb MM (1982) Fuel atomization for spray modelling. Prog Energy Combust Sci 8:61-91. https://doi.org/10.1016/03601285(82)90009-0

85. Hiroyasu H, Kadota T (1976) Fuel droplet size distribution in diesel combustion chamber. Bull JSME 19:1064-1072. https://doi. org/10.1299/jsme1958.19.1064

86. Luangkularb S, Prombanpong S, Tangwarodomnukun V (2014) Material consumption and dry film thickness in spray coating process. Procedia CIRP 17:789-794. https://doi.org/10.1016/j. procir.2014.02.046

87. Perfetti G, Alphazan T, van Hee P et al (2011) Relation between surface roughness of free films and process parameters in spray coating. Eur J Pharm Sci 42:262-272. https://doi.org/10.1016/j. ejps.2010.12.001

88. Xingzhong G, Jie H, Zhonghua N (2012) Optimization of coatings for vascular stent with ultrasonic spray technology. In: Zeng D (ed) Advances in control and communication. Springer, Berlin, pp 547-556. https://doi.org/10.1007/978-3-642-26007-0_68

89. Liu H (1999) Processes and techniques for droplet generation. In: Liu $\mathrm{H}$ (ed) Science and engineering of droplets, 1st ed. Elsevier, Norwich, pp 19-120. https://doi.org/10.1016/B978-0815514367.50003-4

Publisher's Note Springer Nature remains neutral with regard to jurisdictional claims in published maps and institutional affiliations. 